\title{
DISCIPLINA E TRABALHO: Administração de iniciativa na VFRGS
}

Marluza Marques Harres²

A ferrovia, no contexto da sua difusão, foi o símbolo da modernidade, marcando a entrada do mundo na era da velocidade e da integração. A empresa ferroviária guardava em sua estrutura as marcas dos novos tempos e a diversidade de serviços que precisava realizar para efetivar seu funcionamento, a interrelação entre eles, sua distribuição por espaços diferenciados e distantes, são alguns dos seus aspectos característicos. A administração, o gerenciamento deste tipo de empresa ofereceu sérios desafios para os engenheiros, estes artífices da mecânica das engrenagens. Setor especial de atividades onde a experiência do trabalho e sua gestão conformavam-se de modo interligado, assegurando a circulação de bens e pessoas; uma engrenagem invisível, sutil, composta por múltiplos pequenos detalhes perpassava tudo e nos seus interstícios visualizamos o trabalhador ferroviário, ponto nodal, foco e suporte deste maquinismo invisível.

Vanguarda neste tipo de gerenciamento, a difusão das ferrovias pelo mundo na virada do século XIX não apenas facultou a exploração desenfreada das riquezas da terra e da produção, elevadas a uma nova condição como mercadorias, mas levou também a uma nova experiência em termos de trabalho e de gestão a serem implementados

1 Este texto é uma adaptação do primeiro capítulo de minha dissertação de Mestrado, defendida em 1992, no Curso de Pós-Graduação em História da Universidade Federal do Rio Grande do Sul.

2 Professora no Curso de História da Universidade do Vale do Rio dos Sinos (UNISINOS). 
em todos os confins por onde o barulho das engrenagens, o apito e os vapores nebulosos deveriam passar, imprimindo na paisagem a marca dos novos tempos - o domínio da máquina.

Vamos examinar o trabalho dentro da empresa ferroviária buscando dar visibilidade a estes mecanismos que lhe são subjacentes. Nós vamos chamá-los de técnicas de disciplinarização e inspirados no mestre dos micropoderes, Michel Foucault, empreender, não a sua análise global ou total, esta é apenas uma dimensão dos seus efeitos, mas a sua análise em cortes sucessivos, revelando a sua estrutura.

A empresa estudada é a Viação Férrea do Rio Grande do Sul VFRGS, no período que vai de 1920 a 1942; tal recorte delimita uma certa unidade em termos administrativos, o que é importante em nossa perspectiva.

Examinando a documentação relativa ao funcionamento da VFRGS na época considerada percebemos que a administração ali desenvolvida enquadra-se no que Frederick W. Taylor chamava de "Administração de Iniciativa". Neste modelo de administração é dado especial destaque para a relação entre os administradores e os trabalhadores. Taylor em sua obra Princípios da Administração Científica, publicada em 1911, sistematiza de modo resumido as bases da administração de iniciativa. Falando sobre o administrador de sua época ressalta:

Ele acredita que sua função seja induzir o trabalhador a usar a atividade, o melhor esforço, os conhecimentos tradicionais, a habilidade, a inteligência e a boa vontade - em uma palavra sua iniciativa, no sentido de dar o maior rendimento possível ao patrão. O principal problema da administração pode ser, então, resumido em obter a melhor iniciativa de cada operário"3.3.

Neste tipo de administração era comum a utilização de medidas incentivadoras do empenho e da dedicação do empregado ao serviço. Entre estas medidas encontravam-se: gratificaçōes, prêmios, salários mais elevados, melhores condições de trabalho e, por fim, este incentivo especial devia ser acompanhado por "consideração pessoal e amistoso tratamento" ${ }^{4}$. A descrição de Taylor sobre administração de iniciativa deixa transparecer a dependência dos administradores em

3 TAYLOR, Frederick Winslow. Princípios da Administraçāo Científica. 7. ed., Sāo Paulo: Atlas, 1980, p. 47.

4 Ibid. 
relação à experiência, habilidade e vontade dos trabalhadores, sendo fundamental o desenvolvimento de estratégias objetivando assegurar a cooperação dos empregados.

Na VFRGS encontra-se a mesma modalidade de relações envolvendo administradores e empregados. O que não devemos perder de vista é que estas medidas incentivadoras, cuja visibilidade era reforçada, integravam um conjunto mais amplo, fazendo parte da disciplinarização.

Segundo Michel Foucault, os mecanismos disciplinares são bastante antigos, existindo de modo fragmentado até o século XVIII. A partir deste momento o poder disciplinar foi gradativamente aperfeiçoado como uma nova técnica de gestão dos homens ${ }^{5}$. Trata-se de uma nova maneira de gerir a vida dos homens, controlá-los em suas ações, em suas atividades, utilizá-los ao máximo.

Este tipo de poder foi um instrumento fundamental para a constituição do capitalismo industrial e do tipo de sociedade que lhe corresponde ${ }^{6}$. Os métodos e técnicas que põem em funcionamento atingem o indivíduo de modo a torná-lo útil e dócil. Fazem isto integrando-o num sistema de controle e de aperfeiçoamento de suas capacidades, tendo por efeito a maximização de suas forças em termos econômicos de utilidade, ao mesmo tempo em que diminuem ou neutralizam sua capacidade política de revolta e resistência ${ }^{7}$.

Esta docilidade e utilidade produzidas pelas disciplinas foram importantes na transformação dos indivíduos em força de trabalho, condição que implica justamente a domesticação e mercantilização de sua potência criadora. Como indica Foucault, desde o século XVIII essas novas técnicas de poder apareciam nas grandes oficinas, evidenciando-se assim a utilização dos procedimentos disciplinares no processo de sujeição e dominação da força de trabalho.

A minúcia e a variabilidade na aplicação das técnicas disciplinares tornam difícil sua sistematização, podendo-se apontar alguns pro-

5 FOUCAULT, Michel. Microfísica do poder. 8. ed., Rio de Janeiro: Ed. Graal, 1989, p. 105.

6 Ibid, p. 188.

7 MACHADO, Roberto. Introdução: Por uma genealogia do poder. In: Foucault, Michel. Microfísica do poder. 8. ed., Rio de Janeiro: Edições Graal, 1989, p. XVI. 
cedimentos implicados no exercício do poder disciplinar ${ }^{8}$. A disciplina:

- procede a uma distribuição espacial dos indivíduos produzindo a "inserção dos corpos em um espaço individualizado, classificatório, combinatório";

- exerce seu controle sobre a atividade; sobre a ação em seu desenvolvimento;

- implica uma vigilância perpétua e constante dos indivíduos;

- produz um registro contínuo;

- apóia-se no exame, uma vigilância que permite qualificar, classificar e punir.

Analisando a organização da VFRGS encontramos a disseminação de dispositivos disciplinares perpassando as atividades e os trabalhadores nela envolvidos. Podemos dizer que a administração de iniciativa se viabiliza apoiada fundamentalmente nestes dispositivos.

Considerando tal empresa podemos destacar quatro grandes conjuntos de atividades cujo desenvolvimento e integração possibilitavam o serviço de transporte, atividade fim da VFRGS: os serviços das estações e do transporte, estabelecendo o contato com o público usuário; os serviços de conservação da linha férrea; as atividades relativas à manutenção das locomotivas, carros e vagões realizadas nas oficinas e depósitos, abrangendo, além dos serviços de reparo, a montagem e mesmo a construção de veículos; por fim, as determinaçôes sobre a interrelação e a normatização destas atividades integravam os chamados serviços administrativos.

Todas essas atividades implicavam uma diversidade de cargos e profissões, significando a presença de uma mão-de-obra bastante diversificada do ponto de vista ocupacional. Além disso, o número de empregados era expressivo. Em 1926 a empresa possuía 10.211 empregados que atuavam em diversos pontos do Estado do Rio Grande do Sul. Sem dúvida, dada a complexidade de seus serviços e de sua estrutura administrativa, a Viação Férrea era, para a época, uma grande empresa, pioneira no gerenciamento de um contingente tão grande de trabalhadores.

8 FOUCAULT, Michel. Vigiar e punir: nascimento da prisâo. 3. eđ., Petrópolis: Vozes, 1984, passim. 
Na medida em que analisamos as diversas atividades, percebemos a articulação de dispositivos disciplinares na sua própria estruturação. Destacamos alguns cargos e profissões de modo a evidenciar a agilização destes mecanismos.

Entre o pessoal diretamente ligado ao transporte encontram-se, em primeiro lugar, o maquinista, o foguista e o guarda freios. Trabathando nos carros e vagões ficavam os bagageiros, camareiros e os limpadores. Além destes, havia ainda dois cargos que do ponto de vista da direção administrativa apareciam como essenciais: os fiscais e os condutores dos trens.

Todos tinham suas atribuições devidamente estabelecidas em regulamentos. No regulamento de 1925 pode-se constatar a centralidade conferida aos dois cargos. Em relação aos fiscais o regulamento afirma:

"Entre o pessoal de trens, os fiscais são funcionários de maior categoria, pelo que todos os demais empregados, [...] lhes devem obediência e acatamento às suas determinaçōes.

Os fiscais de trens são subordinados imediatos dos inspetores de tráfego e seus ajudantes, de quem receberão instruçốes para agir como convier ao serviço.

Pela sua posição, os fiscais de trens devem ser funcionários de exemplar comportamento tanto privado como público, zelosos no cumprimento de seus deveres, ativos e prontos na execução de ordens recebidas, e enérgicos e justos na repressão de faltas cometidas pelos seus subordinados..." "

Os fiscais e os condutores de trens estavam encarregados do comando e do controle sobre o pessoal que trabalhava nos trens. Entre os requisitos exigidos para o exercício destes cargos sobressaía a confiança e a obediência. No regulamento constava detalhadamente o que deveriam examinar, conferir e executar. Havia, inclusive, orientações sobre a postura mais adequada, como, por exemplo:

"Transmitir ordens aos seus subordinados de modo discreto, em poucas palavras, evitando gritos, conversações à distância e em voz alta". ${ }^{10}$

9 Regulamento Provisório para o pessoal de trens. VFRGS, junho de 1925.

10 Regulamento Provisório para o pessoal de trens. VFRGS, junho de 1925. 
O controle sobre a atuação desses funcionários se fazia através da exigência de preenchimento de impressos padronizados, ou de relatórios, como podemos constatar:

Compete ao Fiscal de trens:

$6^{0}$ - organizar relatórios de inspeção de cada trem que fiscalizar, enchendo o impresso especial para esse fim.

$7^{0}$ - os relatórios devem ser tâo minuciosos quanto possível para o inspetor poder julgar do andamento regular ou irregular do serviço dos trens..."11

Observa-se a existência de uma rede de subordinação envolvendo o próprio pessoal do comando. O empregado, ao assumir um cargo superior, colocava-se também na condição de subordinado. Neste caso, o condutor de trens era subordinado ao fiscal, e o fiscal subordinava-se ao Inspetor do Tráfego de determinada seção. Este, por sua vez, era subordinado ao chefe da Divisão, que respondia perante o Diretor da empresa. Esta hierarquia constituía uma tentativa de garantir o controle sobre os empregados, bem como a obediência às instruções estabelecidas.

As atividades desenvolvidas pela empresa comportavam uma margem de imprevisibilidade, decorrência do próprio tipo de serviço a ser prestado, o transporte de pessoas e mercadorias. A empresa estruturava-se de modo a estar em condições de atender a diversas solicitações, preparando-se para levar determinada carga ou então para conduzir certo número de passageiros. Embora constituísse as condições indispensáveis para a realização da atividade fim a que se propunha, a empresa não tinha como determinar com antecedência e de modo absoluto o tipo de solicitação que deveria atender. De certa forma, o trem que partia às 18 horas de Santa Maria tanto podia sair quase vazio, como podia sair com vários vagões carregados e com carros de passageiros lotados, estando todos desejosos de chegar sem qualquer incidente às 7 horas em Porto Alegre.

Essa imprevisibilidade conferia limites à determinação das tarefas que só podiam ser estabelecidas como possibilidade, pois sua concretização dependia do público usuário. Em função disto eram delimitadas normas gerais de serviço e previstos alguns casos que exigiam medidas especiais. 
De certa forma pode-se dizer que quanto mais precisa for a especificação da atividade, mais fácil é exercer o seu controle. A VFRGS não podia contar com uma delimitação tão rigorosa, mas se valia dos dispositivos de disciplinarização, procurando despertar no empregado a responsabilidade perante o patrimônio da empresa e a coletividade. Um padrão de comportamento era fixado como o mais adequado, pertinente, devendo por isso ser adotado pelos funcionários.

A vigilância deveria, com isto, atentar tanto para a realização das tarefas como para a postura apresentada em serviço. A passagem que segue, de uma circular de 1921, é expressiva a este respeito.

"Recomenda-se aos Srs. Instrutores de maquinistas para fiscalizarem em suas viagens, o modo pelo qual o chefe do trem e seu pessoal atuam nos seus postos.

O Instrutor de maquinistas vos dará parte escrita de qualquer irregularidade encontrada, quer quando o pessoal do trem ficar aglomerado em um só carro, estiver dormindo em marcha ou quer quando não atender ao pedido de freios"12.

A manutenção das velocidades recomendadas, bem como a execução do percurso no tempo previsto, era outro aspecto marcante na atividade do transporte.

Em 1925 algumas locomotivas foram aparelhadas com um velocímetro. Este registrava numa fita de papel, sob forma de um gráfico, a velocidade empregada, a hora e a quilometragem percorrida. Após a viagem, o maquinista entregava a fita para ser examinada pelo chefe do depósito, que a enviava, com as devidas observaçốes, ao Inspetor ${ }^{13}$.

A julgar pelas queixas do engenheiro Frederico Von Bock, os maquinistas logo aprenderam como se livrar deste tipo de controle. É o que se depreende de uma circular de 1927:

"Verifica-se que a porcentagem de velocímetros que funcionam mal é ainda muito elevada. Disso se conclui que a conservação e lubrificaçăo desses aparelhos, assim como a maneira de pô-los em funcionamento, de colocar e retirar a fita gráfica não estão sendo

12 Circular da 3a. Divisão - Locomoção n. 166 de 5 de setembro de 1921.

13 Circular da 3a. Divisão - Locomoção n 10/240 de 11 de novembro de 1925. 
convenientemente cuidadas e observadas, pois não é possível que o número de aparelhos defeituosos seja tão elevado"14 .

A determinação do tempo empregado pelos trens nas viagens, assim como a organização dos horários dos trens de passageiros e de carga nos diversos trechos da rede ferroviária, era tarefa bastante complexa. Em 1923 pretendia-se adotar novos métodos que levassem em conta, além do potencial da locomotiva, as velocidades permitidas pelo estado físico da linha. O projeto envolvendo amplos estudos e cálculos não se concretizou, permanecendo como referência para a determinação dos tempos de percurso entre estações, bem como do tempo para paradas de abastecimento de água ou combustível, as observações feitas em viagens ${ }^{15}$, e registradas em relatórios pelos agentes da fiscalização.

Interessante observar que, desde 1921, era exigido dos maquinistas o registro do tempo gasto em paradas e manobras nas estações. Estas anotações serviam para cálculos do consumo médio de combustível de cada tipo de locomotiva ${ }^{16}$; mas igualmente fornecia o tempo gasto com estas atividades ao longo da viagem. A comparação das informações dos diversos maquinistas dava uma idéia do tempo necessário para manobras e paradas. Desta forma, a própria prática fornecia a base para os ensinamentos a respeito desta atividade. $\mathrm{O}$ que era comum também em outros setores da empresa.

A direção procurava coibir, através de vários dispositivos, inclusive técnicos, os atrasos, as paradas prolongadas, o excesso de velocidade. A vigilância constantemente afirmada, mais do que garantir o controle, serve para suscitar a autodisciplina, o autocontrole. A fiscalização apresentava-se sempre múltipla, vários olhos deveriam ficar atentos aos maquinistas como se pode ver nesta orientação:

... Neste quadro estão traçados os limites de velocidade para uso dos maquinistas que ficam sujeitos à fiscalização do movimento

14 Circular da $2^{\sharp}$ Divisão - Locomoção n. 60 de 29 de junho de 1927.

15 Ata da reuniāo convocada pelo chefe da $3^{\text {a }}$ Divisão. Locomoção. 27 de dezembro de 1923.

16 Circular da $3^{\text {a }}$ Divisão - Locomoção n. 51 de 29 de abril de 1921. 
em cada seção e às informações dos feitores e mestres de linha além da fiscalização que os instrutores maquinistas exercerão"17.

Havia ainda outro tipo de mobilização além da fiscalização. O prazer de ostentar os símbolos do reconhecimento, como levar, por um período de seis meses, na frente da locomotiva um galo de bronze, símbolo da vigilância e, depois, passar a usar no braço esquerdo a estampa de uma locomotiva em miniatura, marca de que havia sido premiado, era um forte estímulo para que os maquinistas buscassem se aproximar do comportamento ideal prescrito pelas chefias ${ }^{18}$.

O serviço de conservação das linhas da Viação Férrea estava organizado com base na formação de grupos de trabalhadores, cada um responsável pela manutenção de um trecho de 10 quilômetros. Cada turma era dirigida por um feitor e supervisionada pelo mestre de linha, que tinha aos seus cuidados 5 turmas. No trabalho usavam ferramentas manuais e deveriam seguir as orientações transmitidas pelo mestre de linha. Havia entretanto ampla margem para a tomada de decisões no serviço, especialmente face aos imprevistos surgidos a partir da ronda diária realizada em cada trecho.

As freqüentes queixas sobre a flexibilidade e a falta de controle e vigilância das chefias em relação aos trabalhadores da linha, revelam a dupla dependência em que se colocavam os administradores. Procuravam assegurar a realização dos serviços inscrevendo os trabalhadores numa hierarquia de comando e vigilância, que, para funcionar, deveria ser respeitada. O mundo do trabalho hierarquizado e normatizado que os administradores se esforçavam por concretizar tinha também outras conotações:

Foi comunicado a esta Diretoria que o mestre de linha da 1a. Residência da Via Permanente, Geraldino Lopes, no período das férias que the foram concedidos, de 23 de fevereiro a 24 de março último, fez uma pescaria em companhia dos trabalhadores de turmas Doro Pereira Padilha e Olmiro Lopes Garcia, e apontou para os referidos trabalhadores, que recebem cada um a diária de

17 Circular da 3a. Divisão - Locomoção n. 141 de 8 de maio de 1922. Encontra-se a indicação do trecho da linha e a velocidade recomendada tanto para trens de passageiros como de carga. Também orienta a respeito das passagens em pontes, viadutos, descidas, etc.

18 A premiação "Emblema de Mérito" foi criada em 1929. 
$6 \$ 000,12$ dias que estiveram na mencionada pescaria, como se os mesmos estivessem em serviço"19.

Este caso deixa entrever uma outra faceta das relações que se estabeleciam entre chefes e empregados, e de como isto podia implicar diferentes posturas frente às regras estabelecidas na empresa. A distância que a escala hierárquia de cargos tentava instituir entre chefes e subordinados era, muitas vezes, quebrada no cotidiano do trabalho. Laços de solidariedade se estabeleciam entre os empregados, pautando de modo diverso as relações entre eles.

Um aspecto relacionado ao serviço das estações sobressai no exame da documentação administrativa. Trata-se da contabilidade das rendas arrecadadas. A fiscalização das contas se fazia a partir das informações fornecidas pelos agentes das estações. Nas diversas seções da Contadoria esta documentação, relativa aos transportes efetuados, era examinada, conferida e confrontada. Entre as disposições regulamentares acerca deste serviço constava:

Art. 104 [...]

$\S 4^{\underline{0}}-\mathrm{A} 3^{\mathrm{a}}$ Sub-seção da Contadoria compete:

a) Conferir diariamente todos os documentos de receita que lhe sejam entregues para escrituração pela $1^{\underline{a}}$ e $2^{\underline{a}}$ Sub-seçōes;

[…]

c) Organizar separadamente para cada estaçāo e manter em dia os documentos do movimento.

[...]

Art. 105 - A verificação dos documentos da receita inclusive os bilhetes de passageiros, cadernetas quilométricas, bilhetes de ingresso e dados estatísticos dar-se-á de modo que em, caso algum, os documentos de uma semana deixem de estar verificados na seguinte. Em caso de afluência de serviço deverâo ser prorrogadas as horas de expedientes, a fim de que no mesmo dia fique terminada a apuração da receita..." 20

Neste tipo de serviço, burocratizado, aparece o cuidado de imprimir uma certa dinâmica nas atividades. Isto era obtido através do entrelaçamento das tarefas em que os serviços executados por uns eram o ponto de partida para o trabalho de outros, estabelecendo-se uma dependência entre as atividades. Este modo de estruturar as ati-

19 Circular da Diretoria n. 241 de 19 de julho de 1932.

20 Regulamento dos Serviços da VFRGS de 1928. 
vidades, ou seja, procedendo a uma divisão do trabalho nos escritórios, criando uma interdependência entre funcionários e serviços, podia transformar-se numa forma indireta de controle e pressão que se desenvolvia entre os próprios funcionários.

Como observa Foucault a respeito da vigilância, "seu funcionamento é de uma rede de relações de alto a baixo; mas também até um certo ponto de baixo para cima e lateralmente; esta rede sustenta o conjunto e o perpassa de efeitos de poder que se apóiam uns sobre os outros: fiscais perpetuamente fiscalizados"21. Sob esta perspectiva pode ser vista a organização dos serviços nos escritórios.

A manutenção e reparo do material rodante - locomotivas, carros e vagões - formavam mais um conjunto de serviços fundamentais em funcionamento na empresa. Os pequenos reparos e os serviços de conservação ordinária desenvolviam-se nos depósitos e nos postos de visita. As reparações maiores e mesmo a construção de carros desenvolviam-se nas oficinas.

Em 1926 a VFRGS possuía três oficinas - em Santa Maria, Rio Grande e Gravataí - encarregadas de todo o serviço de reparação do material rodante. Para a manutenção regular dos veículos havia 17 depósitos e 27 postos de visita espalhados pelas 5 seções de tração, trechos de linha.

Estes serviços reuniam grande contigente de trabalhadores, tanto qualificados como sem ofício definido.

Envolvidos na conservação e abastecimento dos veículos podese destacar os empilhadores de lenha, os carvoeiros, limpadores, reparadores de carros, visitadores, ajustadores, entre outros. Nas oficinas concentravam-se especialmente os trabalhadores mais qualificados, de cuja habilidade e experiência muito dependia a administração. Entre esses encontravam-se torneiros mecânicos, fundidores, funileiros, ferreiros, soldadores, pintores, carpinteiros e vidraceiros.

Os serviços nas oficinas organizavam-se através de seções, cada seção com grupos de trabalhadores sob o comando de um chefe de turma, que distribuía e orientava os trabalhadores. Acompanhavam os serviços os contramestres de seção e os contramestres gerais, comandados todos pelo Chefe da oficina. A título de ilustração, relacionamos:

21 FOUCAULT, Michel. Vigiar e punir: nascimento da prisão. 3. ed., Petrópolis:

Vozes, 1984, p. 158. 


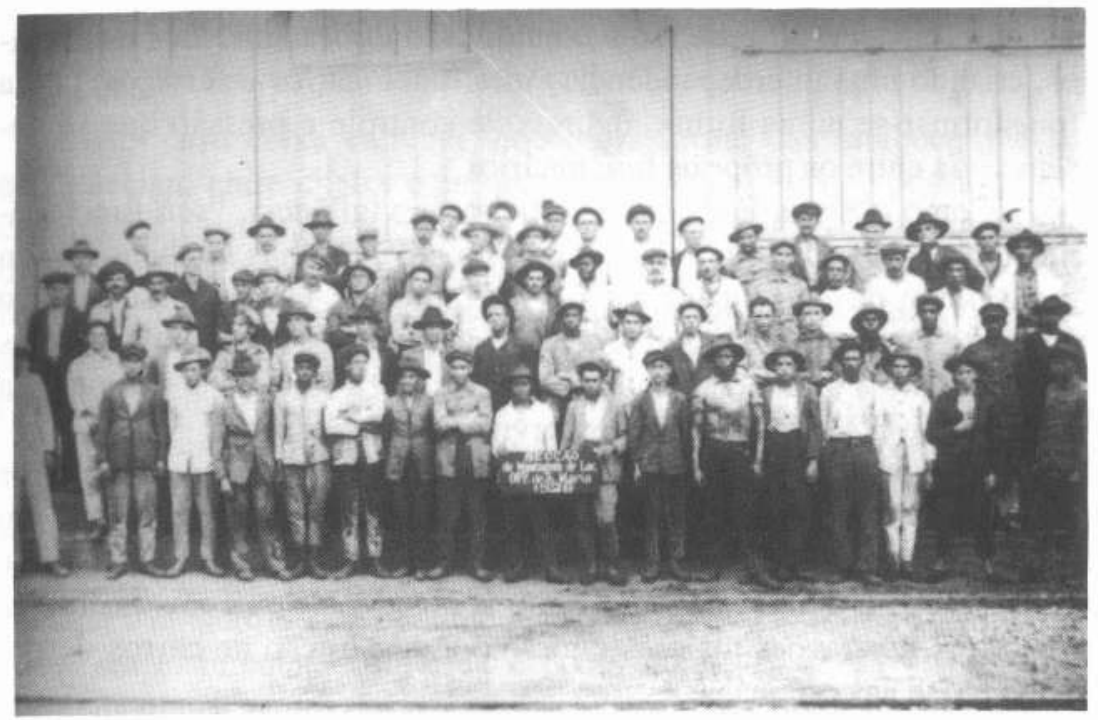

Trabalhadores da seção de montagem de locomotivas da Oficina de Santa Maria, 1928.

“...

Contra mestres da seção de tornos .................................. 2

Chefes de turmas de torneiros........................................ 2

Torneiros mecânicos..................................................... 46

Ajudantes de torneiros mecânicos .............................. 6

Aprendizes de torneiros mecânicos ............................. 2 2"22

Os trabalhadores das oficinas foram os que mais se destacaram na resistência ao reordenamento que se processou na VFRGS a partir da sua encampação, em $1920^{23}$, pelo Governo Estadual. Os trabalha-

22 Relatório da Diretoria da VFRGS. 1920.

23 A precariedade dos serviços ferroviários no Rio Grande do Sul foi motivo de insatisfações e queixas de vários grupos sociais que sentiam-se prejudicados em seus negócios. A pressão sobre as companhias estrangeiras, encarregadas da construção e administração das ferrovias gaúchas nâo apresentava resultados. A situação acabou favorecendo as pretensōes do governador Borges de Medeiros de assumir o controle administrativo das ferrovias do Estado, o que ocorreu em julho de 1920. Desenvolvendo-se a partir de então um amplo programa de reestruturação da empresa. 
dores não aceitaram o novo contramestre nomeado para a seção de tornos da oficina de Rio Grande. A mobilização iniciada nessa seção foi gradativamente se expandindo, conseguindo paralisar completamente os serviços nas oficinas entre 8 de setembro e 6 de outubro de 1920. O movimento iniciado em Rio Grande atingiu também as oficinas de Santa Maria.

Tal movimento é indicativo da resistência dos trabalhadores às mudanças introduzidas pela Direçấo Administrativa. A vigilância cerrada, o emprego de punições, e as multas produziam forte insatisfação. As novas medidas entravam em choque com costumes e práticas estabelecidos. A resistência manifestar-se-ia também de outras formas, mas a paralisação se destaca pelo caráter coletivo e solidário que teve.

A Direção se manteve intransigente e acabou demitindo sete empregados considerados os principais cabeças, instigadores da greve. Na perspectiva dos administradores, a questão se resolvia pela exclusão dos chamados "maus elementos" ${ }^{24}$.

A importância e o papel que a Direção reservava às novas chefias evidenciava-se nesse episódio. A greve, ao mesmo tempo que explicita a rede de solidariedade tecida entre os trabalhadores, envolvendo inclusive as antigas chefias intermediárias, revela também a estratégia usada pela nova Direção para melhorar o aproveitamento da mão-de-obra. Principiaram por reforçar a vigilância sobre o trabalho, nomeando novos chefes imediatos, no trabalho é que sua ação deveria se fazer sentir sendo, inclusive, controlado e pressionado a este respeito pelo chefe da Divisão.

A circular que a seguir transcrevemos, além de mostrar a pressão que se fazia sobre as chefias imediatas, possibilita entrever um outro mundo do trabalho.

"Srs. Chefes de Oficinas - puniçōes e responsabilidades.

Há muito tempo vos chamei a atenção para falta que venho observando da aplicação de puniçốes ao pessoal operário sob vossas ordens.

Parece que a aplicação de penalidades neste departamento somente é um privilégio da Tração, onde os encarregados de serviço servem-se deste meio para corrigir as faltas disciplinares do pessoal operário. 
Não quero crer, porém, que nas oficinas, onde trabalham centenas de operários, não hajam sobejos motivos para punições corretivas e que não podem e não devem deixar de ser aplicadas.

Em pessoa tenho visto operários que descansadamente fazem cigarros, trocam idéias com seus companheiros e perdem o precioso tempo do trabalho que assim lhes é pago indevidamente.

Na seção de reparações de carros e vagões, onde mais facilmente os operários podem trocar conversações inúteis e perturbar assim a marcha do serviço, tenho visto tais irregularidades.

Daí o fato, de no fim do mês, ter-se uma fraca produção de carros e vagōes preparados.

Tendes da minha parte toda a força moral para exercerdes a vossa ação enérgica e justiceira e, portanto, deveis reunir os vossos contra mestres e dar-lhes ordens terminantes peremptórias para que os abusos cessem, para que as punições apareçam como corretivos necessários às irregularidades diárias no serviço" 25 .

Outro ritmo pautava a atuação dos empregados, contrariando os interesses dos administradores. Estes estavam preocupados em promover a utilidade máxima do tempo, aumentando com isso a produção. Tratava-se de garantir a aplicação constante, ininterrupta do empregado no serviço, durante todo o tempo em que estava, por força do contrato de trabalho, à disposição da empresa.

Como observa Foucault, "o tempo medido e pago deve ser também um tempo sem impureza nem defeito, um tempo de boa qualidade, e durante todo o seu transcurso o corpo deve ficar aplicado a seu exercício. A exatidão e a aplicação são, com a regularidade, as virtudes fundamentais do tempo disciplinar"26.

Aumentar a produção das oficinas esteve sempre entre as preocupações da Direção Administrativa. A remodelação e construção de novas oficinas foram logo providenciadas, melhorando as condições gerais de trabalho. A atenção voltou-se para a manutenção de um ambiente limpo e arejado, para a vigilância e orientação dos trabalhadores e para a compra de equipamentos. A partir de 1929 cogita-se, inclusive, na introduçāo de "métodos modernos de racionalização do trabalho" nas oficinas ${ }^{27}$. Pensavam estabelecer novas formas de con-

25 Circular da 3a. Divisão - Locomoçâo n. 114 de 23 de junho de 1921.

26 FOUCAULT, Michel. Vigiar e punir: o nascimento da prisão. 3 ed., Petrópolis: Vozes, 1984, p. 137.

27 Relatório da Diretoria da VRFGS. 1929. 
trole da produção, medidas concretas que, entretanto, não chegaram a se efetivar, alegando a Direção falta de pessoal qualificado.

A chamada "organização científica do trabalho" inspira-se principalmente nas proposições de Frederick W. Taylor. A própria expressão foi utilizada pela primeira vez por este autor para designar os processos de trabalho que se estruturassem com base no pressuposto da separabilidade total entre planejamento e execução. A empresa deveria desenvolver departamentos de estudo e planejamento de modo a produzir as normas para a realizaçāo das tarefas. Isto implicava a decomposição/recomposição das tarefas de modo a estabelecer a melhor combinação de movimentos, melhor no sentido do aproveitamento máximo do tempo. Todos os movimentos deveriam ser previamente determinados e os trabalhadores orientados e vigiados na execução das tarefas. Para o seu idealizador, este método poderia ser aplicado com qualquer tecnologia, inclusive no trabalho manual ${ }^{28}$.

Gramsci aponta os objetivos expressos na proposta Taylorista de organização do trabalho:

“...Desenvolver ao máximo no trabalhador as atitudes maquinais e automáticas. Romper o velho nexo psicofísico do trabalho profissional qualificado, que exigia uma determinada participação ativa da inteligência, da fantasia, da iniciativa do trabalhador e reduzir as operaçōes produtivas ao aspecto físico maquinal", ${ }^{29}$

Devemos lembrar que ao enunciar sua proposta de administração científica, também chamada administração de tarefas, Taylor desqualificava a prática administrativa comum na sua época, designada por ele como administração de iniciativas. Fica clara a contraposição dos dois sistemas, um centrado na iniciativa dos trabalhadores, o outro apoiado na idéia de uma precisa delimitação de tarefas individuais. A proposta Taylorista criava um novo método para o controle dos trabalhadores que lhes retirava, completamente, a possibilidade de determinar os processos e o ritmo do seu trabalho.

Entre o empresariado brasileiro, a preocupação com a mudança dos métodos de trabalho apareceu na década de 20 , justamente em meio ao acirramento dos conflitos trabalhistas. Como demonstra Ma-

28 TAYLOR, Frederick Wislow. Princípios da Administração Científica. 7. ed., São Paulo: Livraria Pioneira Ed., 1981.

29 GRAMSCI, Antonio. Maquiavel, a política e o Estado moderno. 5. ed., Rio de Janeiro: Civilização Brasileira, 1984, p. 397. 
ria Antonieta Antonacci ${ }^{30}$, parte do empresariado vislumbrou na reorganização do trabalho em bases científicas uma saída para os conflitos, comportando mesmo a reafirmação do domínio do capital no espaço da produção. Buscando incentivar e subsidiar experiências nesta área, foi criado em São Paulo o Instituto de Organização Racional do Trabalho em 1931. A VFRGS manteve, na década de 40, intercâmbio com esta instituição que forneceu orientações e material relacionado à seleção e aperfeiçoamento profissional.

$\mathrm{Na}$ VFRGS o interesse em torno das propostas racionalizadoras também apareceu ligado ao setor onde os conflitos na esfera do trabalho eram mais intensos: nas oficinas.

A administração de iniciativa parecia encontrar seus limites na politização dos trabalhadores, na organização de um movimento operário, na denúncia da exploração, inerente à apropriação do trabalho no capitalismo. O trabalho tornava-se território de luta e de disputas colocando em questão o modelo de trabalhador - pontual, aplicado e obediente - visado pela disciplinarização. É neste novo contexto de luta que as práticas modernas de gestão do trabalho ganharam destaque.

Considerando o setor de prestação de serviços, dentro do qual se enquadrava a VFRGS, a implementação da chamada administração científica apenas podia se fazer de modo limitado. Isto porque a previsibilidade e o controle sobre a tarefa, no lugar da centralidade dada ao comportamento e à conduta, era a essência da nova prática administrativa. Para Claus $\mathrm{Offe}^{31}$ a previsibilidade possível na produção industrial, em que todos os passos do processo do trabalho podem ser previamente determinados, diminuindo-se ao mínimo a margem para os acasos e os imprevistos, não pode ser estendida ao setor de prestação de serviços. Neste setor cada atendimento é um caso, sujeito a variaçôes e, além disso, a simultaneidade com que se processa a produção e o consumo é outra característica marcante que acaba conferindo uma certa indeterminação ao processo de trabalho. É de se pensar que a incorporação dos princípios de organização científica do

30 ANTONACCI, Maria Antonieta Martinez. A vitória da razão: o instituto de organização racional do trabalho - 1931 a 1945. Tese de Doutorado, USP, 1985 .

31 OFFE, Claus. Trabalho e sociedade: problemas estruturais e perspectivas para o futuro da "Sociedade do Trabalho". Rio de Janeiro: Tempo Brasileiro, 1991, v. 2, passim. 
trabalho nas empresas ferroviárias tenha sido seletiva, pois apenas alguns setores, como as oficinas, se enquadravam dentro da sua lógica.

Ilustra bem a distância guardada pela VFRGS em relação à chamada "administração científica" o concurso criado em 1930 com o nome de "Prêmio às Idéias". Era oferecido um prêmio em dinheiro ao funcionário que apresentasse projetos e sugestões cuja aplicação tivesse por conseqüência "sensível melhoria ou economia para os serviços" ${ }^{\prime 32}$.

Conforme a circular de divulgação do concurso:

"Raros serão os funcionários que não digam entre si:

- se eu ocupasse tal cargo, o desempenharia de modo muito mais conveniente.

É exatamente isso que esta inspetoria deseja saber [...] tão somente uma idéia de como um órgão qualquer da Viação Férrea possa ser aperfeiçoado..." ${ }^{33}$.

A experiência, a iniciativa e a colaboração dos trabalhadores continuava a ser esperada, estimulada e prestigiada.

Mesmo tendo centrado nossa atenção no processo do trabalho, não devemos esquecer que a disciplinarização abrange um universo mais amplo, penetrando a vida familiar, o lazer, as associaçōes operárias e as instâncias de formação profissional. No contexto do acirramento das disputas trabalhistas tivemos a disseminação mais intensa dos mecanismos disciplinares por estes outros lugares, alguns mantidos na esfera de influência da empresa, outros patrocinados pelas associações de empresários ou ainda pelo Estado. Os objetivos? Sem dúvida eram múltiplos, mas como técnica de gestão dos homens, o poder disciplinar faculta a ótima aplicação das forças humanas sua utilização concentrada e dirigida, o aproveitamento do tempo em termos de sua aplicação ao "trabalho útil".

32 Circular da Diretoria n. 221 de 23 de agosto de 1930.

Ibid. 